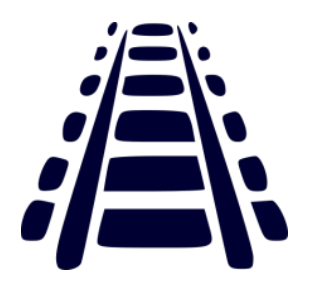

Demiryolu Mühendisliği

http://dergipark.org.tr/demiryolu

Temmuz 2020, Say1:12, Sayfa: 43-51

e-ISSN: 2687-2463, ISSN: 2149-1607

Araştırma Makalesi

\title{
Dinamik Fren Kullanımının Yük Vagonu Tekerleklerine Gelen Isıl Yüke Etkisinin Gerçek İşletme Şartlarında Deneysel Olarak İncelenmesi
}

\author{
Nail KARAGÖZ *1® ${ }^{*}$, Halil İbrahim ACAR²® \\ ${ }^{1}$ TÜDEMSAŞ Genel Müdürlüğü Ar-Ge Dairesi Başkanlı̆̆l, Sivas, Türkiye \\ ${ }^{2}$ Cumhuriyet Üniversitesi Müh. Fakültesi Makine Mühendisliği Bölümü, Sivas, Türkiye \\ *nailkaragoz@hotmail.com
}

(Alınış/Received: 31.05 .2020 , Kabul/Accepted: 24.06.2020, Yayımlama/Published: 31.07.2020)

Öz: Bir yük treninin frenleme işleminde hava freni ve yardımcı bir fren olan dinamik fren kullanılır. Hava freninde, fren pabucu (sabo) ile tekerlek yuvarlanma yüzeyi arasında oluşturulan sürtünme kuvveti frenlemeyi sağlar. Dinamik frende ise tren katarının hızının azaltılması için cer motorları bir jeneratör gibi kullanılmakta ve böylece trenin kinetik enerjisi elektrik enerjisine dönüştürülmektedir. Ülkemizde yük vagonu taşımacılığında kullanılan lokomotiflerin yaklaşık \% 42'sinde dinamik fren bulunmamaktadır.

Vagonların aşağı yönlü hareketinde, bazı güzergâhlarda, vagon hızını kontrol amaçlı, uzun süreli "sürükleme freni" yapılması gerekmekte, bu durum tekerleklerde çok yüksek sıcaklıklar oluşmasına sebep olabilmektedir. Oluşan bu yüksek sıcaklıklar sebebiyle çok çeşitli tekerlek hasarları oluşmakta ve bu durum demiryolu güvenliğini azaltmaktadır.

$\mathrm{Bu}$ çalışmada, tekerlek 1sınması sebebiyle tekerlek hasarlarının sıkça gözlemlendiği Gümüş-Yenice arasında (ortalama eğim \%13,4 ve toplam uzaklık $94 \mathrm{~km}$ ) çalışan iki konteyner vagonunda seyrüsefer boyunca tekerlek yuvarlanma yüzeyinde oluşan sıcaklıklar, vagon hızı, fren silindirlerinde oluşan basınç verileri kaydedilmiştir.

Tam dolu olan test vagonlarının bulunduğu katar, 12 adet Rgns vagonu ve DE 33000 dizel lokomotiften oluşturulmuştur. O bölgede hâlihazırda çalışan ve dinamik freni olmayan lokomotiflerin de kullanılması sebebiyle Hacıkırı - Durak istasyonları arasında lokomotifte bulunan dinamik fren devre dışı bırakılmış sadece hava freni kullanılmıştır.

Gerçek işletme şartlarında yapılan test sonuçlarına göre dinamik frenin devre dışı bırakıldığı, istasyonlar arası rakım farkının 350 m olduğu Hacıkırı-Durak istasyonları arasında tekerleklere gelen frenleme enerjisi, vagon başına 363,7 MJ'dür. Buna karşın, dinamik frenin kullanıldığı Gümüş- Pozantı istasyonları arasında, rakım farkının daha fazla olmasına rağmen $(515 \mathrm{~m})$, bu değer vagon başına yalnızca $58,6 \mathrm{MJ}$ olarak gerçekleşmiştir. Test boyunca, dinamik frenin kullandığı bölgelerde tekerleğin yuvarlanma yüzeyinin sıcaklıklar $100{ }^{\circ} \mathrm{C}$ civarında iken dinamik frenin kullanılmadığı Hacıkırı-Durak istasyonları arasında (22 $\mathrm{km})$ tekerleğin yuvarlanma yüzeyi sıcaklığ $350{ }^{\circ} \mathrm{C}$ 'ye kadar yükselmiştir ve ayrıca bu güzergâhta bir saboda parça kopması da gözlenmiştir.

Anahtar kelimeler: Dinamik fren, Hava freni, Tekerlek 1sınması, Yük vagonu, Saha testi

\section{Experimental Study of the Effect of Dynamic Brake on the Thermal Load of Freight Wagon Wheels in Real Operating Conditions}

Abstract: The braking of a freight train is provided by the air brake and the dynamic brake, which can be regarded as a secondary brake system. In the air brake, the braking is provided by the friction force between the brake block and the rolling surface of the wheel. In dynamic braking, traction motors are used as a generator to reduce train speed, thus, the kinetic energy of the train is converted into electrical energy. In Turkey, approximately $42 \%$ of the locomotives used in the transportation of freight cars do not have dynamic brakes.

Atıf için/Cite as: N. Karagöz, H.İ. ACAR, "Dinamik fren kullanımının yük vagonu tekerleklerine gelen 1sıl yüke etkisinin gerçek işletme şartlarında deneysel olarak incelenmesi," Demiryolu Mühendisliği, no. 12, pp. 43-51, July. 2020. doi: 10.47072/demiryolu.746023 


\section{Demiryolu Mühendisliği}

In downhill movement of the wagons, on some rail routes, "drag brake" must be applied for a long time to control the wagon speed, which can lead to very high temperatures in the wheels. Due to these high temperatures, a wide variety of wheel damages can occur and this reduces railway safety.

In this study, temperature of the wheel rolling surface, wagon speed, and pressure of the brake cylinders were recorded in two container wagons running between Gümüş-Yenice where wheel damage was observed frequently due to wheel warming. Average inclination between Gümüş-Yenice is \%o 13.4 and total distance $94 \mathrm{~km}$.

The train is composed of 12 fully loaded Rgns test wagons and a DE 33000 diesel locomotive. Due to the fact that also the locomotives without dynamic brakes were currently used in that area, the dynamic brake in the locomotive was canceled and only the air brake was used between Hac1kır1-Durak stations.

According to the test results made under real operating conditions, the braking energy applied to the wheels between Hac1kırı and Durak station where the dynamic brake was disabled is $363.7 \mathrm{MJ}$ per wagon (the altitude difference between stations is $350 \mathrm{~m}$ ). On the other hand, although the altitude difference is bigger $(515 \mathrm{~m})$ between Gümüş-Pozantı stations where dynamic brake was used, braking energy applied to the wheel is only 58.6 MJ per wagon. During the test, on the rail routes where dynamic brake was used, temperatures of the rolling surface of the wheels are around $100^{\circ} \mathrm{C}$. On the other hand, between the Hacikir1 and Durak station $(22 \mathrm{~km}$ ) where the dynamic brake is not used, the temperature of the rolling surface of the wheel has increased up to $350{ }^{\circ} \mathrm{C}$, and it was observed that a small piece was broken from the brake block.

Keywords: Dynamic brake, Air brake, Wheel warming, Freight wagon, Field test.

\section{Giriş}

Yük vagonu fren sisteminde frenleme için gerekli fren kuvveti, fren silindirinde bulunan basınçlı hava ile oluşturulmaktadır. Manivelalarla fren pabucuna iletilen bu kuvvet, fren pabucu (sabo) ile tekerlek yuvarlanma yüzeyi arasında sürtünme kuvveti oluşturur. Yük vagonlarında hızın ve taşıma kapasitesinin artmasıyla birlikte aşağı yönlü eğimin büyük olduğu uzun mesafelerde, vagon hızının kontrol edilebilmesi için uygulanan uzun süreli çekme freni, tekerlekler üzerinde ciddi isıl yükler oluşturmaktadır. Tekerlek üzerindeki ısıl yük, birçok tekerlek ve sabo hasarlarının oluşmasına sebebiyet verebilmektedir. Yardımcı bir fren olan dinamik frenin lokomotifte bulunması durumunda tekerleklere gelen ssıl yük azalacaktır. Ancak ülkemizde yük vagonu taşımacılığında kullanılan lokomotiflerin yaklaşık \% 42'sinde dinamik fren bulunmamaktadır [1].

TÜDEMSAŞ'a bakıma onarıma gelen birçok vagonda 1sıl kaynaklı tekerlek hasarlarına rastlanmaktadır. 2018 yılında, Gümüş (Niğde)-Yenice (Adana) istasyonları arası çalışan 14 adet Rgns tipi konteyner vagonunda 1sıl sebeplerle oluşmuş tekerlek hasarları tespit edilmiş ve bu konuyla ilgili TÜDEMSAŞ Genel Müdürlügü, 16.07.2018 tarihli ve 56095775-000 E.11569 sayılı yazı ekinde yer alan bir rapor hazırlamıştır.

Bu çalışmada, sürekli aşağı yönlü hareketin olduğu, hızın kontrol edilebilmesi için çok sık fren yapılması sebebiyle tekerlek 1sınma probleminin en sık görüldüğ̈̈ güzergâhlardan biri olan Gümüş-Yenice istasyonları arasında çalışan vagonlarda, dinamik fren uygulamasının tekerleğe gelen ısıl yükün azaltılmasına etkisi, gerçek servis şartlarında deneysel olarak incelenmiştir.

\section{Metot}

Maksimum hızı $120 \mathrm{~km} / \mathrm{h}$ 'i geçmeyen yük vagonlarında endirekt hava freni kullanılır. Vagonun durdurulması, yavaşlatılması veya hızının sabit tutulması amacıyla yapılan frenleme işlemi, tekerlek yuvarlanma yüzeyi ve sabo arasında oluşturulan sürtünme kuvveti ile sağlanır. Endirekt hava frenli sistemde, freni çözülmüş durumda olan bir vagonun fren hattında 5 bar basınçlı hava bulunur. Bu hava, distribütör valfi yardımıyla yardımcı hava deposunu (rezerve) 5 bar havayla 


\section{Demiryolu Mühendisliği}

doldurur. Yardımcı hava deposu distribütör valfi ile silindir arasında bulunmaktadır. Frenleme esnasında fren hattındaki (kondüvit) basınç düşürülür. Basınç düşmesi sebebiyle fren hattından distribütöre hava akışı durur, yardımcı hava deposundaki basınçlı hava distribütör valfi üzerinden fren silindirine gider. Maksimum 3,8 bar basınçlı havanın oluşturduğu kuvvet manivelalar yardımıyla sabolar üzerinden tekerleklere iletilir. Bu şekilde frenleme gerçekleştirilmiş olur. Frenin çözülmesi için fren hattındaki basınç tekrar 5 bar seviyesine getirilir, distribütör valfi yardımıyla bir taraftan basınçlı hava tekrar yardımcı hava rezervesini doldururken diğer taraftan fren silindirindeki hava boşaltılır [2]. Lokomotiflerde ise, depolanmış basınçlı hava yardımıyla frenlemeyi sağlayan direkt ve endirekt hava fren sistemi bulunmaktadır. Bu frenleme sistemlerine ek olarak lokomotiflerde dinamik frenleme sistemi de bulunabilmektedir. [3]. Dinamik frenin bulunduğu lokomotiflerde atalet momentine sahip olan tren hızının azaltılması için cer motorları bir jenaratör gibi kullanılmakta ve böylece trenin kinetik enerjisi elektrik enerjisine dönüştürülmektedir. Üretilen elektrik tekrar kullanılması için katener hattına verilebilir (rejeneratif dinamik fren sistemi) veya dirençler üzerinde 1sıya dönüştürülerek havaya verilir (reostatik dinamik fren sistemi) [4]. Sürtünmeye bağlı olmayan bir fren türü olan dinamik fren kullanımı hava freni kullanımını azalttığı için tekerlekle sabo arası oluşan ısıl yükü, dolayısıyla tekerlek ve sabo aşınmasını ve 1sıl hasarlarını azaltır. Test treninde kullanılan DE33000 tipi lokomotifte reostatik dinamik fren sistemi bulunmaktadır.

Test treni, TÜDEMSAŞ tarafindan üretilen TSI sertifikalı 12 adet kompakt frenli Rgns konteyner vagonundan ve dinamik freni bulunan DE33000 tipi dizel lokomotiften oluşturulmuştur. Test vagonlarında yüksek sürtünme katsayılı Cosid $810 \mathrm{~K}$ tipi kompozit fren sabosu kullanılmaktadır. 2006 yılında Avrupa'da gürültü sınır değerleri belirlenmiş, 2012 yılında Avrupa Birliği ve OTIF dokümanlarıyla bu sınır değerler uygulanmaya başlanmıştır. Pik döküm sabo kullanımı ile bu sınır değerler sağlanamadığı için pik döküm sabo yerini kompozit sabolara bırakmıştır [5].

Rgns vagonu için Knorr Bremse firmasının hazırladığı fren hesabında yer alan, silindir basıncı, silindir basıncı ve manivela oranlarına bağlı olarak değişen sabo kuvveti, sabo kuvvetine bağlı Cosid 810-K tipi sabonun sürtünme katsayıs1 ve sabo kuvvetinin sabo sürtünme katsayısıyla çarpımına eşit olan tekerlek başına düşen fren kuvveti Tablo1.'de verilmiştir. Silindir basıncının ara değerleri için fren kuvveti interpolasyon yöntemiyle bulunabilir.

Tablo 1. Fren kuvvetini belirleyen parametreler

\begin{tabular}{ccccc}
\hline $\begin{array}{c}\text { Vagon } \\
\text { A } \breve{g} 1 \text { lı̆ } 1 \\
\text { (ton) }\end{array}$ & $\begin{array}{c}\text { Silindir } \\
\text { Basıncı } \\
\text { p (bar) }\end{array}$ & $\begin{array}{c}\text { Sabo Kuvveti } \\
\text { Fs }(\mathrm{kN})\end{array}$ & $\begin{array}{c}\text { Cosid 810 K- Dinamik } \\
\text { Sürtünme Katsayısı }(\mu)\end{array}$ & $\begin{array}{c}\text { Tekerlek Başına } \\
\text { Düşen Fren Kuvveti } \\
(\mathrm{kN})\end{array}$ \\
\hline 19,5 & 1,03 & 6,79 & 0,327 & 2,22 \\
25 & 1,27 & 8,85 & 0,325 & 2,88 \\
30 & 1,52 & 11 & 0,311 & 3,42 \\
40 & 2,12 & 16,14 & 0,29 & 4,68 \\
50 & 2,93 & 23,09 & 0,26 & 6,00 \\
$58-90$ & 3,6 & 28,84 & 0,24 & 6,92 \\
\hline
\end{tabular}

Gümüş istasyonunda test için tam dolu iki vagon seçilmiştir. Önceden hazırlanan aparatlar yardımıyla Micro-Epsilon marka CTM-3SF33 model iki adet kızılötesi sıcaklık sensörü, boji üzerine tekerleğin yuvarlanma yüzeyinden yaklaşı $200-230 \mathrm{~mm}$ uzağa monte edilmiştir. Fren silindirinin basınc1, fren valfi üzerinde bulunan, basınç ölçüm noktasına yerleştirilen iki adet "iFm" marka "PU8504" model basınç sensörü ile ölçülmüştür. Lokomotifte hız kayıt cihazının arızalı olması sebebiyle lokomotifin hız kadranının video kaydı alınmış ve bu kayıttan yararlanarak hız zaman grafiği çıkarılmıştır. Hız zaman grafiğinden yararlanarak bulunan yol, istasyonlar arası uzaklığın verildiği demiryolu haritaları ile uyumlu olup fark \%1'den azdır. Test 


\section{Demiryolu Mühendisliği}

verilerini toplamak için "Nationel Instrument" marka "NI USB 6002 ve NI USB 6211" model iki adet PC tabanlı veri toplama kartı kullanılmıştır. Sistem her saniye bir veri alacak şekilde programlanmıştır. Şekil 1.'de Gümüş istasyonunda, seçilen test vagonlarına test düzeneğinin yerleştirilmesi görülmektedir.

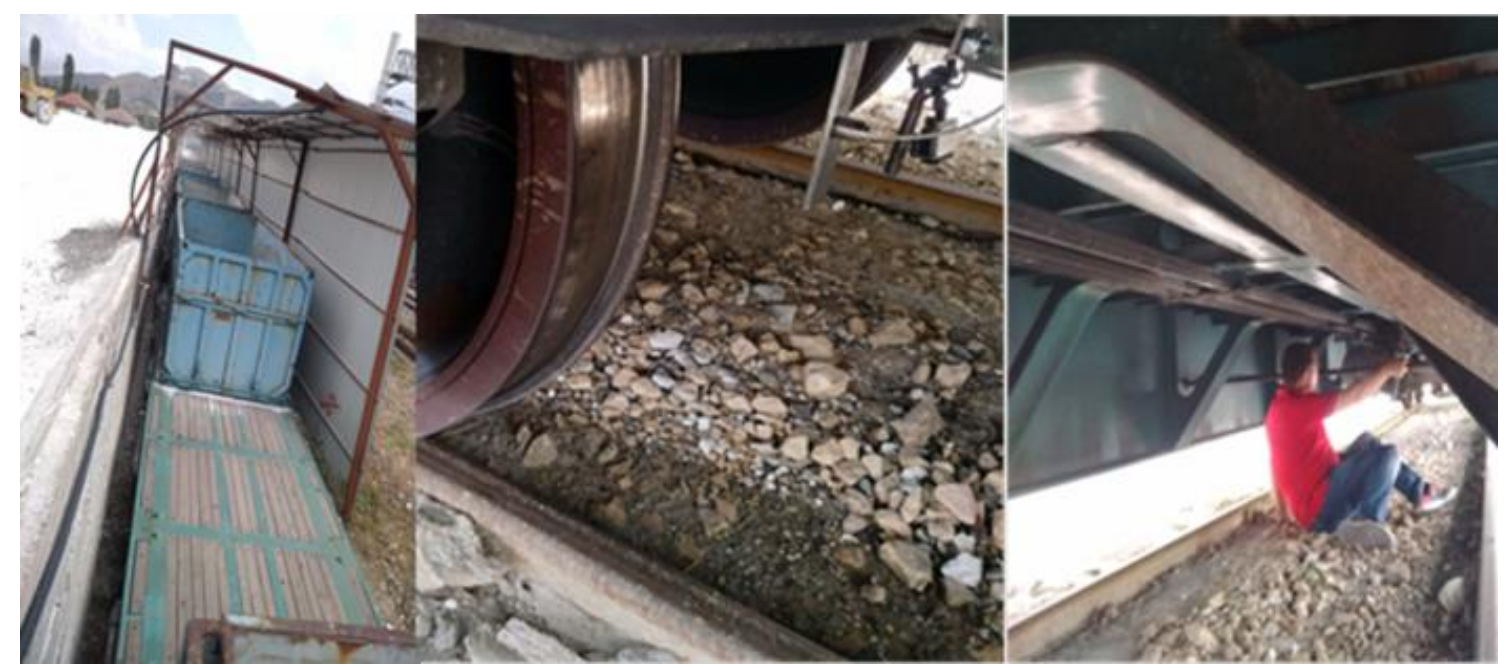

Şekil 1. Gümüş istasyonu test vagonları test düzeneğinin yerleştirilmesi

Test rüzgârsız bir havada gerçekleşmiştir. Hava sıcaklığı yaklaş1k $22^{\circ} \mathrm{C}$ hava nem oranı yaklaşık \% 65'dir. Test güzergâhı üzerinde bulunan istasyonlara ait rakım, eğim, mesafe ve hız değerleri Tablo 2. ve Tablo 3.'de verilmiştir.

Tablo 2. Test güzergâhı mesafe ve rakım değerleri

\begin{tabular}{lccccccc}
\hline \multicolumn{1}{c}{ Test Güzergâhı } & Gümüş & Çiftehan & Pozantı & Belemedik & Hacıkırı & Durak & Yenice \\
\hline Gümüşs’e uzaklığı $(\mathrm{m})$ & 0 & 15077 & 30724 & 40388 & 55193 & 77171 & 93862 \\
Rakım $(\mathrm{m})$ & 1293 & 949 & 778 & 703 & 600 & 250 & 34 \\
\hline
\end{tabular}

Tablo 3. Test güzergâhı eğim ve hız değerleri

\begin{tabular}{lccc}
\hline \multicolumn{1}{c}{ Test Güzergâhı } & Eğim (\%) & $\begin{array}{c}\text { Bekleme Hariç } \\
\text { Ortalama Hız (km/h) }\end{array}$ & $\begin{array}{c}\text { Varışta Bekleme } \\
\text { Süresi (s) }\end{array}$ \\
\hline Gümüş-Çiftehan & 22,8 & 37 & 0 \\
Çiftehan-Pozantı & 10,9 & 36,8 & 243 \\
Pozantı -Belemedik & 7,8 & 36,2 & 2341 \\
Belemedik-Hacıkırı & 7,0 & 31,8 & 900 \\
Hacıkırı-Durak & 15,9 & 32,3 & 1919 \\
Durak-Yenice & 12,9 & 49,7 & 100 \\
\hline
\end{tabular}

\section{Bulgular}

Gerçek servis şartlarında yapılan saha testinde hıza ve frenleme işlemine makinist karar vermiş, ancak dinamik fren olması ve olmaması durumunda tekerleğe gelen frenleme enerjisinin nasıl değiştiğini tespit edebilmek için Hacıkırı-Durak istasyonları arasında dinamik fren devre dışı bırakılmıştır. Tekerlek sabo arasında oluşan isıl enerjinin tespiti için en önemli veriler silindir basıncı ve hız verileridir. Testte iki vagonda silindir basınçları ayrı ayrı ölçülmüştür. İki vagon için silindir basıncı değerleri oldukça yakındır. Hacıkırı-Durak istasyonları için silindir basınç değerleri Şekil 2.'de verilmiştir. 


\section{Demiryolu Mühendisliği}

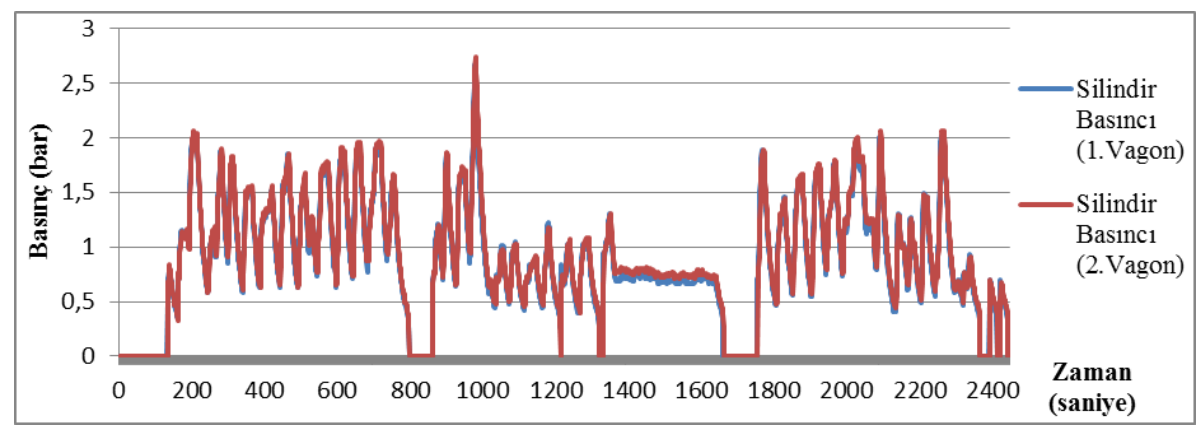

Şekil 2. Vagonların fren silindir basınçlarının zamana göre değişim grafiği

Dinamik frenin kullanılmadığı yalnızca hava freninin kullanıldığı Hacıkırı - Durak istasyonları arasında tam fren (silindir basınc 13,8 bar) hiç uygulanmamıştır. Silindir basıncı 0,7 bar ile 2,1 bar arasında olacak şekilde frenleme yapılmış ve frenlemelerden yalnızca birinde silindir basıncı 2,1 bar'ı geçmiştir (2,7 bar). Hacıkırı-Durak istasyonlar arası elde edilen basınç verileri ve Tablo 1.'de yer alan verilerden yararlanılarak hesaplanan tekerlek başına düşen frenleme kuvvetinin zamana karşı değişimi Şekil 3.'de verilmiştir.

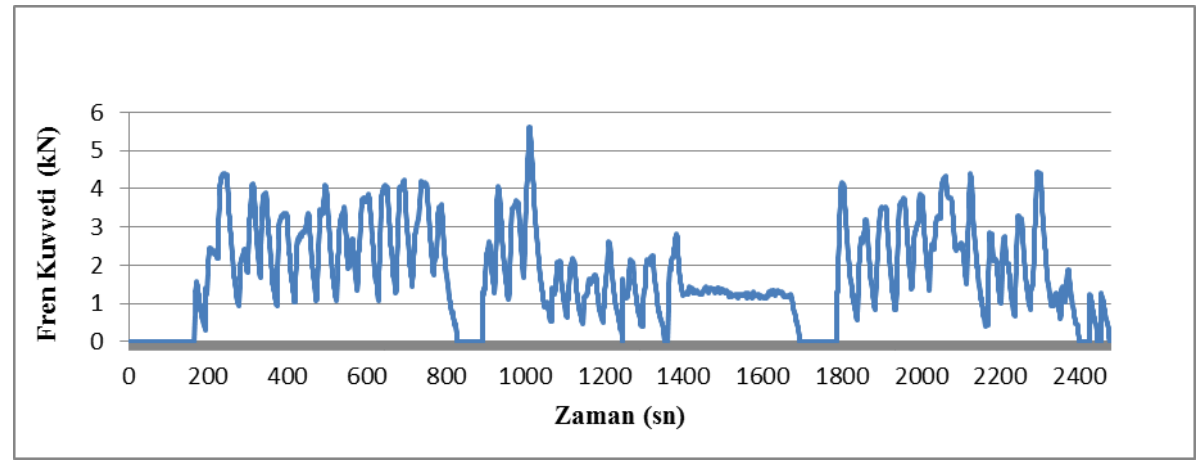

Şekil 3. Tekerlek başına düşen fren kuvvetinin zamana göre değişimi

Ayrıca ortalama hızın yaklaşık $32 \mathrm{~km} / \mathrm{h}$ olduğu Hacıkırı-Durak istasyonları arasında vagon hızının en büyük değeri 58 km/h'dir. Şekil 4.'de Hacıkırı-Durak istasyonları arası hız değerleri verilmiştir.

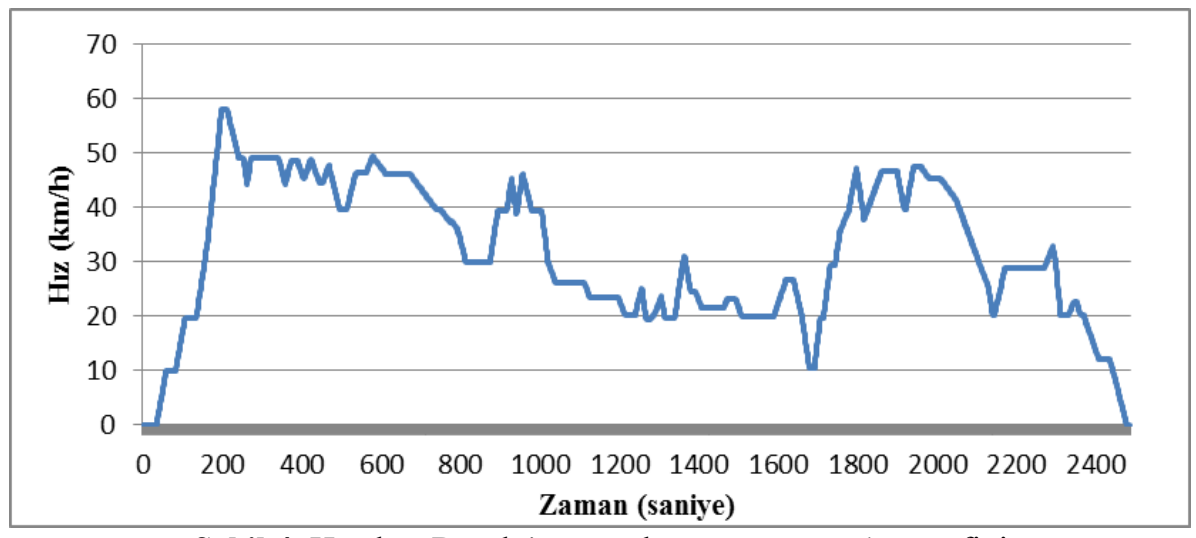

Şekil 4. Hacıkırı Durak istasyonları arası vagon hız grafiğgi

Tekerlek ile sabo arasında oluşan 1sıl enerjiyi belirleyen en önemli parametre fren gücü ve uygulama süresidir. Fren kuvveti ve vagon hızının çarpılması ile fren gücü bulunabilir. Hacıkırı Durak istasyonları arası fren gücünün zaman bağlı değişimi Şekil.5'de verilmiştir. 


\section{Demiryolu Mühendisliği}

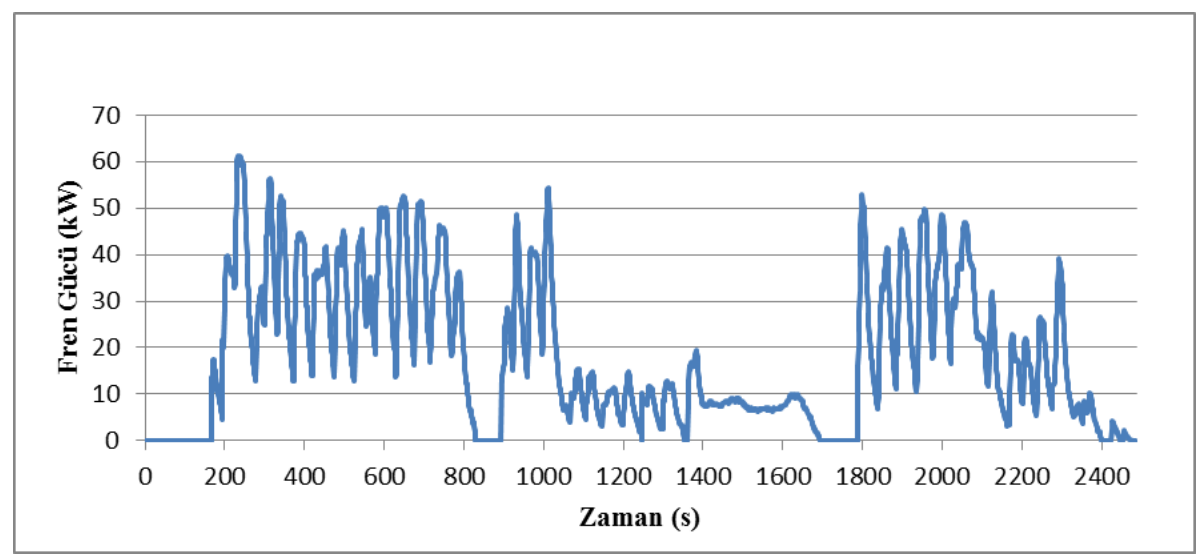

Şekil 5. Hacıkırı-Durak istasyonları arası zamana bağlı fren gücü grafiği

Dinamik frenin kullanılmadığı Hacıkırı - Durak istasyonu ile Dinamik frenin kullanıldığı GümüşPozant1 istasyonları arası hareket, dinamik kullanımının tekerlek ray arası oluşan frenleme enerjisine etkisinin karşılaştırılması için oldukça uygun görülmektedir. Her iki durum için, uygulanan hava freni sebebiyle, tekerlek sabo arasında oluşan fren gücünün zamana bağlı grafiği Şekil 6.'da verilmiştir. Grafiğin altında kalan bölgenin alanı bir tekerleğe gelen frenleme enerjisini vermektedir.

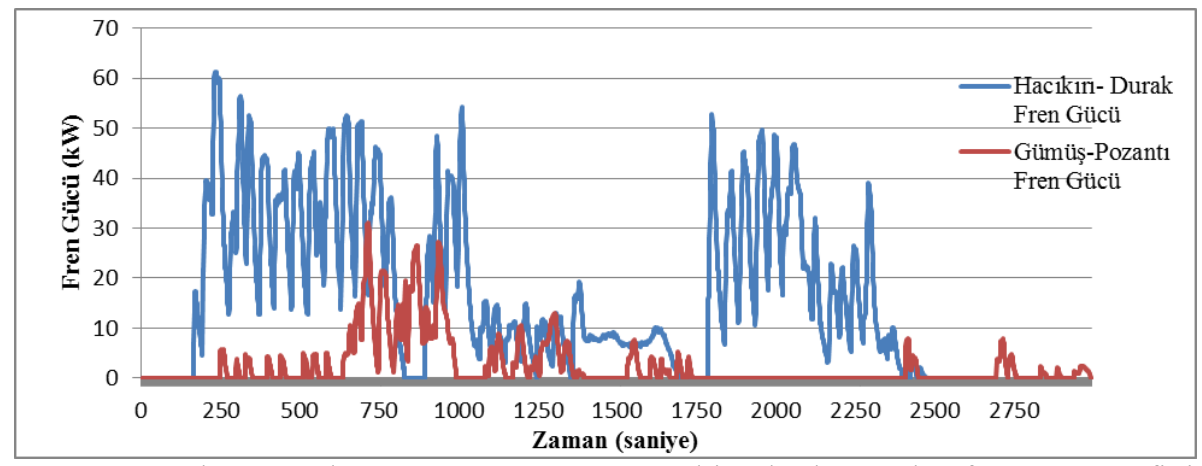

Şekil 6. Hacıkırı-Durak ve Gümüş-Pozantı arası bir tekerleğe gelen fren gücü grafiği

Frenleme sebebiyle tekerlek başına 1sıya dönüşen enerji Hacıkırı-Durak istasyonları arasında $45469 \mathrm{~kJ}$ (bir vagon için 363,7 MJ), Gümüş-Pozantı istasyonları arasında ise $7322 \mathrm{~kJ}$ (bir vagon için 58,6 MJ) olarak ölçülmüştür. Sürekli aşağı yönlü harekette toplam frenleme enerjisini etkileyen en önemli parametre çok büyük oranda iki istasyon arası yükseklik farkından kaynaklanan potansiyel enerjidir. Tablo 4.'de istasyonlar arası bir vagon için potansiyel enerji farkı ve uygulanan frenleme enerjisi verilmiştir.

Tablo 4. Güzergâhlara göre uygulanan frenleme enerjisi karşılaştırması

\begin{tabular}{lcc}
\hline \multicolumn{1}{c}{ Test Güzergâhı } & Hacıkırı-Durak & Gümüş- Pozantı \\
\hline Rakım Farkı (m) & 350 & 515 \\
Ortalama Eğim (\%o) & 15,9 & 16,8 \\
Bir Vagon İçin (90 ton) İstasyonlar Arası Potansiyel & 308,7 & 454,7 \\
Enerji Farkı (MJ) (m.g.h) & 363,7 & 58,6 \\
Tekerlek- Sabo Arası Oluşan Frenleme Enerjisi (MJ) & 117,8 & 17,5 \\
Frenleme Enerjisinin, Potansiyel Enerjiye Oranı (\%) & & \\
\hline
\end{tabular}

Tablo 4.'de görüleceği gibi bir vagon için dinamik frenin uygulanmadığı Hacıkırı-Durak istasyonları arasında frenleme enerjisi, istasyonlar arası potansiyel enerji farkının \%117,8'si iken 


\section{Demiryolu Mühendisliği}

dinamik frenin uygulandığı Gümüş-Pozantı istasyonları arasında bu değer \%17,5'idir. Dinamik frenin uygulandığı ortalama eğimi \% 12,9 olan Durak-Yenice istasyonları arasında ise vagona uygulanan frenleme enerjisi, istasyonlar aras1 potansiyel enerji farkının \%12,9'u dur. Verilere göre dinamik fren kullanılması durumunda 1200 tonluk bir tren katarı için, eğimin büyük olduğu bölgelerde, vagonlarda tekerleklere uygulanan frenleme enerjisi yaklaşı $\% 85$ civarında azalmaktadır. Dinamik fren kullanımın tekerleğe gelen 1sıl yükü azaltmaya katkısı yol eğiminin azalmasıyla daha da artmaktadır.

Dinamik frenin kullanıldığı durumlarda tekerlek yuvarlanma yüzeyi sıcaklığını en yüksek değerleri $100^{\circ} \mathrm{C}$ civarında iken, dinamik frenin kullanılmadığı, aralarında $22 \mathrm{~km}$ mesafe bulunan Hacıkırı-Durak istasyonları arasında bu sıcaklık $250{ }^{\circ} \mathrm{C}$ artarak yaklaşı $350{ }^{\circ} \mathrm{C}$ değerlerine ulaşmıştır. Ayrıca bu süreçte Şekil 7.'de görüleceği üzere UIC onaylı kompozit bir saboda parça kopması gerçekleşmiştir. Saboda parça kopmasının gerçekleşmesi durumunda o sabo değiştirilir.

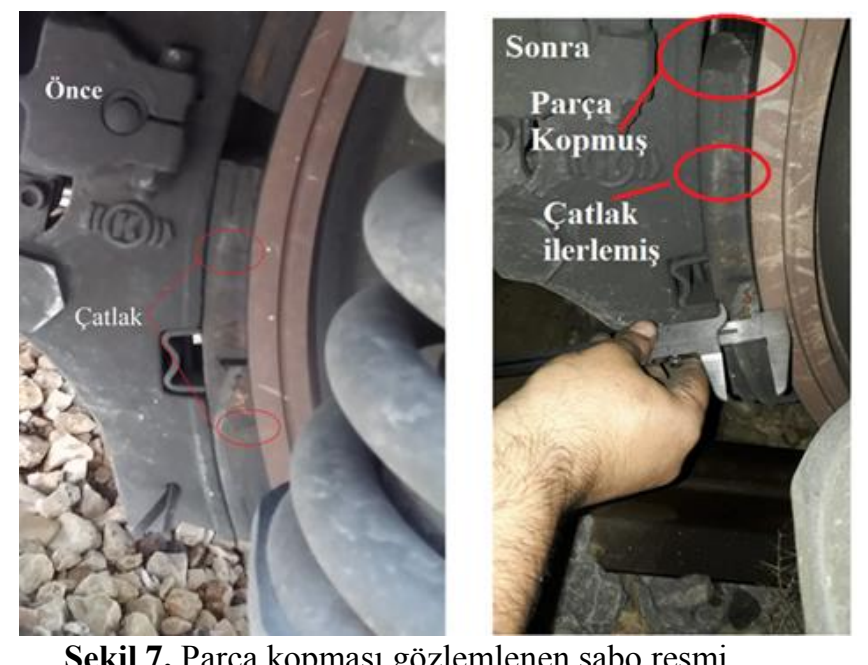

Kompozit saboların onaylanması için yapılan ve UIC tarafından test sonuçları yayınlanan “Avrupa Treni Projesi”nin sonuçlarından biri Tablo.5'de verilmiştir [7]. Gerçek işletme şartlarında yapılan bu test sonucuna göre $10.000 \mathrm{~km}$ 'de kompozit sabo, ortalama 2,2 $\mathrm{mm}$ aşınmaktadır (dolu ve boş vagon ortalaması).

Tablo 5. Pik sabo ve LL saboda aşınma oranı

\begin{tabular}{cccccc}
\hline \multicolumn{5}{c}{ Sabo aşınma oranı $[\mathrm{mm} / 10.000 \mathrm{~km}]$} \\
\hline Pik Sabo & Pik sabo & LL-C952 & LL-C952 & LL-IB116 & LL-IB116 \\
Boş vagon & Dolu vagon & Boş vagon & Dolu vagon & Boş vagon & Dolu vagon \\
\hline 2,14 & 8,00 & 0,82 & 1,70 & 1,31 & 4,92 \\
\hline
\end{tabular}

\section{Sonuç}

Seyrüsefer esnasında eğimin fazla ve uzun olduğu güzergâhlarda frenlemeyle birlikte tekerleğin genel sıcaklığı artar, yuvarlanma yüzeyindeki sıcaklık çok daha büyük değerlere ulaşır ve tekerleğin raya değmesi sonucu (yaklaşık temas yüzeyi alanı $1 \mathrm{~cm}^{2}$ ) yuvarlanma yüzeyinde sıcaklığı farklı anlık bölgeler oluşabilir. Tekerlek yuvarlanma yüzey sıcaklığındaki $200{ }^{\circ} \mathrm{C}$ değişiklik yaklaşık $700 \mathrm{MPa}$ kadar ısıl gerilim oluşturabilir. Bu durum kalıcı şekil değişimine, yuvarlanma yüzeyinde çekme kalıntı gerilimine ve tekerlek yüzeyinde sertleşmeye, 1sıl çatlaklara sebep olabilir [6]. Ayrıca çelik malzemede sıcaklığın $200{ }^{\circ} \mathrm{C}$ artması akma mukavemetini yaklaşık $\% 20$ düşürmektedir [8]. 


\section{Demiryolu Mühendisliği}

TCDD Taşımacılık A.Ş. 2018 istatistik yıllı̆̆ taşımacılığında kullanılan toplam lokomotifin (elektrikli lokomotifler dâhil) yaklaşık \% 42'si hâlihazırda dinamik freni olmayan DE24000 tipi lokomotiftir. DE24000 tipi lokomotiflerin projesinde dinamik fren bulunmakla beraber ilk 60 adet lokomotiften sonra üretilen lokomotiflerde dinamik fren yapılmamış, dinamik freni olan lokomotiflerde de dinamik fren zaman içinde sökülmüş̧ür [9]. Dinamik fren, trende hızı kontrol etmek için kullanılan yardımcı frendir. Test sonuçları değerlendirildiğinde, lokomotiflerde bulunan dinamik frenin kullanılmasının küçük tonajlı (800-1200 ton) tren katarında oldukça etkili olduğu görülmektedir. Dinamik frenin kullanıldığ 1 Gümüş - Pozantı ve Durak - Yenice arası alınan veriler ile dinamik frenin kullanılmadığı Hacıkırı - Durak istasyonları arasında alınan veriler karşılaştırıldığında, dinamik fren kullanımında büyük eğim değerlerine sahip güzergâhlarda tekerlek-sabo arası 1sıya dönüşen frenleme enerjisi, yaklaşı \% 85 oranında azalmakta ve yol eğiminin azalmasıyla birlikte dinamik fren kullanımı hava freni kullanımını daha da azaltmaktadır. Isıl kaynaklı tekerlek ve sabo hasarlarının azaltılması için eğimin fazla olduğu bu hatlarda dinamik freni olmayan lokomotiflerin kullanımından mümkün olduğu kadar kaçınılmalıdır.

Test vagonunda UIC onaylı Cosid 810 marka $\mathrm{K}$ tipi sabo kullanılmıştır ve yolun dinamik frenin kullanmadığ yaklaşı $22 \mathrm{~km}$ bölümünde saboda parça kopması gözlemlenmiştir. Parça kopmas1 olan sabolar mevcut talimatlar gereği değiştirilmelidir. UIC destekli "Avrupa Tren Projesi" kapsamında LL Tipi saboların saha testleri yapılmıştır. Tablo 5.'de verilen test sonuçlarına göre $10.000 \mathrm{~km}$ de ortalama sabonun aşınma miktarı 2,2 $\mathrm{mm}$ arasındadır. Bu aşınma değerleri ve sabonun yaklaşık $50 \mathrm{~mm}$ kalınlığında ki bir bölümünün işletmede kullanılabileceği dikkate alınacak olursa, ortalama sabo ömrü ömrünün yaklaşık 200 bin km olabileceği söylenebilir. Test Avrupa demiryollarında yapılmıştır bu sebeple Türkiye'nin kendine özgü coğrafi ve işletme şartları dikkate alınacak olursa ortalama sabo ömrünün 200 bin km'nin bir miktar altında gerçekleşmesi beklenebilir. Türkiye'nin yakın zamana kadar yılda yaklaşık 300 bin adet saboya ihtiyacı olduğu yetkililerce ifade edilmiştir [10]. Türkiye'de toplam vagon ve dingil sayısı ve yılda kat edilen ortalama dingil.km değerleri esas alınacak olursa, tekerlek başına düşen sabo sayısı vagonlara göre değişebildiği için net bir sonuca ulaşamamakla beraber, sabo ömrünün 40 bin - 60 bin $\mathrm{km}$ arasında olduğu değerlendirilmektedir. Sabo ömrüyle alakalı resmi bir bilgiye ulaşılamamıştır. Yapılan testte dinamik frenin uygulanmadığ $22 \mathrm{~km}$ içinde sabodan parça kopması, dinamik freni olmayan lokomotiflerin eğimin fazla olduğu uzun güzergâhlarda kullanılmasının tekerlek ömrünün yanında sabo ömrünü de ciddi oranda azalttığını göstermektedir. Bu tür lokomotifler daha uygun güzergâhlarda çalıştırılmalı ve mümkünse mevcut projesinde olduğu gibi dinamik fren eklenmelidir. Tekerlek ve saboda oluşacak 1sıl hasarların kazaya sebebiyet vermesi sonucu can mal kaybı ve çevre felaketlerine yol açabileceği dikkate alınmalıdır. Ayrıca sabodan yüksek sıcaklıktaki bir parçanın kopması sonucu ülkemizde birçok tarım arazisi ve orman yangınlarına da sebep olduğu bilinmektedir ve test verileri dikkate alındığında bu durumun en önemli sebeplerinden birinin bu hatlarda dinamik freni olmayan lokomotiflerin kullanılmasının olabileceği değerlendirilmektedir.

\section{Kaynakça}

[1] TCDD Taşımacılık A.Ş., 2018 İstatistik Ylllı̆̆ı Özeti. Ankara, 2018.

[2] N. Karagöz, " Bir yük vagonun uzun süreli frenlenmesi sonucu açığa çıkan 1sının iki farklı tekerlek seti üzerindeki dağılımının sayısal analiz metodu ile incelenmesi." Yüksek lisans tezi, Fen Bilimleri Enstitüsü, Cumhuriyet Üniversitesi, Sivas, 2015.

[3] Milli Eğitim Bakanlığı, Raylı Sistemler Teknolojisi, Çeken Araç Fren Sistemi. Ankara, 2011.

[4] N. Saville, "Engineering studies train braking systems," Newcastele Division Education Committee, 2017.

[5] Ö. Akbayır, "Yük vagonlarında kullanılan sabolar ve karşılaştırması," 1.Uluslararası Raylı Sistemler Mühendisliği Çalıştayl, Karabük, Türkiye, 2012.

[6] E.A.G. Hernandez, "Wheel and rail contact simulation using a twin disc tester," Ph.D. dissertation, The University of Sheffield, 2008. 


\section{Demiryolu Mühendisliği}

[7] UIC International Union of Railways, Synthesis Paper on the Europe Train Operation with LL Brake Blocks Final Report. 2013.

[8] Capacity4Rail, Novel rail freight vehicles. Project received funding from European Union's, 2016.

[9] E. Tönük, "DE 24000 MTE-Alsthom TÜLOMSAŞ (ELMS) Dizel Elektrik Lokomotifi (Co'Co')," [Online]. Available: http://users.metu.edu.tr/tonuk/E40003/24000/ [Accessed June 1, 2020].

[10] Teknosektör haber, [Online]. Available: http://teknosektor.com/2014/03/20/trenler-icin-yerliuretim-fren-balatasi-gelistirildi/ [Accessed June 1, 2020].
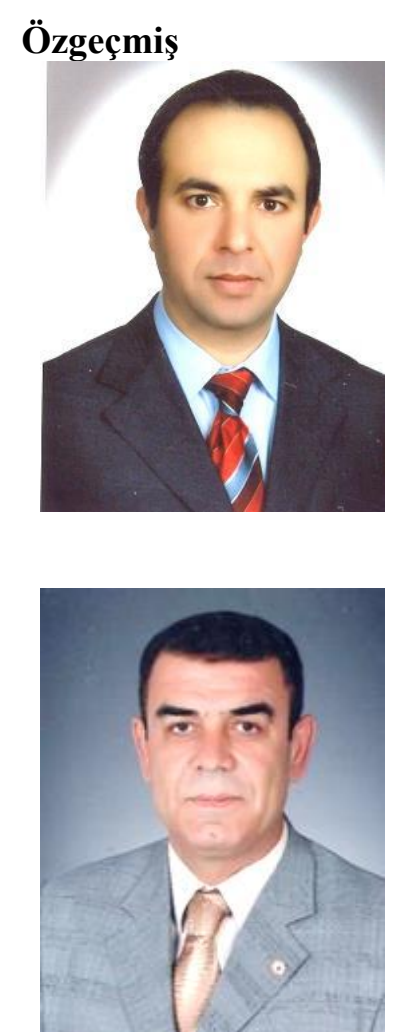

\section{Beyanlar}

\section{Nail KARAGÖZ}

1972'de Berlin'de doğmuştur. Lisans eğitimini 1995 y1lında Orta Doğu Teknik Üniversitesi'nde tamamlamıştır. Yüksek lisans eğitimini (2015) ve doktora eğitimini (2020) Cumhuriyet Üniversitesi'nde tamamlamıştır. Halen yük vagonu üretimi ve bakımı yapan TÜDEMSAŞ'ta Ar-Ge Dairesi Başkanlığında makine mühendisi olarak görev yapmaktadır. A-Sınıfı iş güvenliği uzmanı ve tahribatsız muayene-seviye 2 UT uzmanıdır. Evli ve üç çocuk babasidir.

E-Posta: nailkaragoz@ hotmail.com

\section{Halil İbrahim ACAR}

1958 Sivas doğumlu.1981 y1lında Sakarya DMMO 'dan mezun oldu. Cumhuriyet Üniversitesi Sivas MYO'da çalışmaya başladı. 1992'de Yrd. Doç., 1997'de doçent ve 2003' de Prof. unvanı aldı. Halen Makina Mühendisliği bölüm başkanlığını yürütmektedir. Evli ve iki çocuk babasıdır. İngilizce ve Almanca bilmektedir. Çalışma Konuları: Termodinamik ve Isı Tekniği, Yeni ve Yenilenebilir Enerji Teknolojileri, Isıtma, Soğutma, İklimlendirme uygulamaları.

E-Posta: iacar@cumhuriyet.edu.tr

$\mathrm{Bu}$ makalede bilimsel araştırma ve yayın etiğine uyulmuştur.

Tüm yazarların eşit oranda katkısı olmuştur. 